\title{
Rancang Bangun Smart Assistant Lengan Robot Penghapus Papan Tulis
}

\author{
Retyana Wahrini ${ }^{1}$, Labusab $^{2}$, Nuridayanti ${ }^{3}$ \\ 1,2,3 Pendidikan Vokasional Mekatronika, Fakultas Teknik Universitas Negeri Makassar, Indonesia \\ ${ }^{1}$ retyana.wahrini@unm.ac.id*, ${ }^{2}$ ochalabusab@unm.ac.id, ${ }^{3}$ nuridayanti@unm.ac.id \\ * corresponding author
}

\begin{abstract}
The blackboard is one of the facilities that is still widely used in the learning process in Indonesia. This is because most educational methods have not been fully touched by digital technology, especially in remote areas. In deleting the writings on the board, it takes time, even more draining. We need to know that removing the blackboard is an activity that is not liked by students because it must be done repeatedly. To overcome this problem, one solution that can be done is to make an automatic eraser tool. This whiteboard eraser is based on a sound sensor. The working process is through the voice commands given, the Smart Assistant is designed to make it easier for us to delete the writing on the board. The design of the Smart Assistant is more effective where the program uses a sound sensor system with the Voice Recognation method, so that when we want to erase the whiteboard we just have to sound according to the commands we have programmed on the Arduino Software so the whiteboard will be deleted.
\end{abstract}

Article Info

\author{
Article history \\ Received: Oct. $19^{\text {th }}, 2020$ \\ Revised: Nov. $30^{\text {th }}, 2020$ \\ Accepted: Nov. $30^{\text {th }}, 2020$
}

Keywords

Voice Recognation,

EasyVR,

Papan Tulis.

\begin{abstract}
ABSTRAK
Papan tulis merupakan salah satu sarana yang masih banyak digunakan dalam proses pembelajaran di indonesia. Hal ini dikarenakan sebagian besar metode pendidikan belum sepenuhnya tersentuh teknologi digital terkhusus daerahdaerah terpencil. Dalam menghapus tulisan-tulisan di papan tulis membutuhkan waktu terlebih lagi menguras tenaga. Perlu kita ketahui bahwa menghapus papan tulis merupakan aktivitas yang tidak disenangi oleh para siswa karena harus dilakukan berulang-ulang. Mengatasi masalah ini, salah satu solusi yang bisa dilakukan adalah membuat sebuah alat penghapus otomatis. Penghapus papan tulis ini berbasis sensor suara. Penelitian ini menggunakan jenis penelitian R\&D dengan metode waterfall. Proses kerjanya yaitu melalui perintah suara yang diberikan maka Smart Assistant ini dirancang untuk memudahkan kita dalam menghapus tulisan pada papan tulis. Perancangan Smart Assistant ini lebih efektif dimana program ini menggunakan sistem sensor suara dengan metode Voice Recognation, sehingga saat kita ingin menghapus papan tulis cukup dengan kita bersuara sesuai dengan perintah yang telah kita program pada software arduino dengan begitu papan tulis akan dihapus oleh alat tersebut.
\end{abstract}

\section{PENDAHULUAN}

Menurut UU No.23 Tahun 2003 tentang SIKDIKNAS, Pendidikan adalah usaha sadar dan terencana untuk mewujudkan suasana belajar dan proses pembelajaran untuk peserta didik secara aktif mengembangkan potensi dirinya untuk memiliki kekuatan spiritual keagamaan, pengendalian diri, kepribadian, kecerdasan, akhlak mulia, serta keterampilan 
yang diperlukan dirinya, masyarakat, bangsa dan nagara.

Salah satu aspek yang seharusnya mendapat perhatian utama adalah pengelolaan sarana dan prasarana pendidikan. Pengelolaran sarana dan prasarana sangat penting karena dengan adanya pengelolaan sarana dan prasarana lembaga pendidikan akan terpelihara dan jelas kegunaanya. Sarana pendidikan umumnya mencakup semua fasilitas yang secara langsung dipergunakan dan menunjang proses pendidikan.

Pada kegiatan ini dirancang sebuah alat yaitu Smart Assistant Lengan Robot Penghapus Papan Tulis (whiteboard) dimana program ini menggunakan metode voice recognation dengan sensor suara EasyVR melalui pengucapan pada aplikasi handphone yang telah dibuat serta interface penggunaan tombol yang diprogram pada Arduino.

Easy Voice Recognition (EasyVR) merupakan voice recognition yang multifungsi. EasyVR dapat digunakan pada banyak aplikasi pengendalian yang membutuhkan pendeteksian suara ataupun percakapan. EasyVR menggunakan suara sebagai masukan. Suara yang masuk kemudian diolah dan dicocokkan dengan perintah suara yang telah diatur atau ditetapkan.

Penggunaan voice recognition system memungkinkan seseorang mengucapkan kata dalam bahasa yang dikenal oleh sistem yang kemudian diterjemahkan ke dalam suatu katakata. Pengenalan suara merupakan proses dimana komputer atau mesin lainnya mengidentifikasi kata-kata yang diucapkan. EasyVR mendukung beberapa bahasa, antara lain English (US), Italia, Jerman, Francis, Spanyol, dan Jepang.

Pengenalan suara manusia atau human voice recognition adalah sebuah teknologi yang mana suara yang terdengar, kata, atau frasa yang diucapkan oleh manusia diubah menjadi sinyal-sinyal listrik. Sinyal-sinyal ini diubah menjadi kode-kode yang terpola dan ditetapkan. Menurut Xinyu (2013: 74) menjelaskan bahwa dengan adanya voice control maka pengguna hanya memerlukan satu kata atau satu kalimat untuk mengaktifkan dan mematikan sesuatu. Pengguna tidak perlu mengingat dan peduli fungsi tombol. Menurut Gupta (2015:1) menjelaskan bahwa kit pengenalan suara praktis digunakan untuk menyimpan dan mengenali suara pengguna. Dalam hal ini ketika suara manusia sudah diubah menjadi kode-kode, maka kode tersebut digunakan untuk mengendalikan suatu sistem yang ada.

Rancangan sistem dari alat ini adalah dapat melakukan penghapusan papan tulis sesuai dengan perintah suara yang diberikan kemudian lengan robot akan menghapusnya.

\section{METODE}

Proses perancangan alat dilaksanakan dengan tahapan dalam Gambar 1.

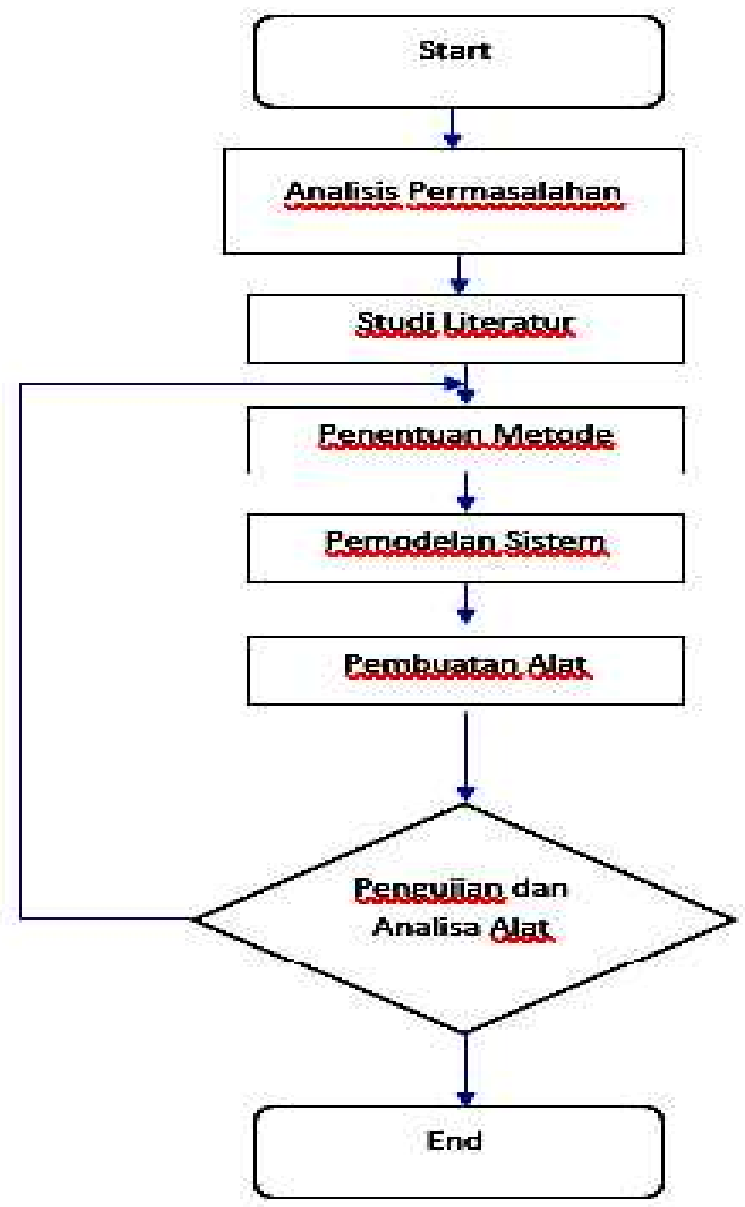

Gambar 1. Diagram Perancangan Alat

Pada tahap analisis permasalahan, penulis mendalami latar belakang permasalahan dan 
mengamati keadaan terkini terkait permasalahan yang akan diselesaikan. Dengan demikian, penulis dapat melakukan studi literatur yang tepat dalam perancangan alat.

Pada tahap studi literatur penulis mencari dasar teori yang tepat dalam merancang alat, sistem kerja arduino dan motor sebagai penggerak lengan robot. Melakukan literatur yang berhubungan dengan metode pengolahan voice recognation pada sensor suara EasyAVR dari penghapus papan tulis. Dari studi literatur ini dapat dikelompokkan alat dan bahan apa saja yang diperlukan dalam pembuatan alat. Kegiatan ini dilakukan dengan mencari materi penunjang dari buku, paper, dan artikel.

Tahap penentuan metode dilakukan dengan menggunakan metode Voice Recognation. Perangkat lunak pengenalan suara pada alat yang mengharuskan audio analog diubah menjadi sinyal digital yang dikenal sebagai konversi analog-ke-digital Agar program ini dapat menguraikan sinyal, harus memiliki basis data digital, atau kosa kata, kata-kata atau suku kata, serta cara cepat untuk membandingkan data ini dengan sinyal. Pola bicara disimpan di hard drive dan dimuat ke dalam memori saat program dijalankan. Ukuran dari kosakata yang efektif dari pengenalan suara secara langsung berkaitan dengan kapasitas memori akses acak dari arduino.

Proses pemodelan sistem dilakukan untuk mendapatkan pemodelan elektronik dalam perancangan Smart Assistant Lengan Robot Penghapus Papan Tulis (Whiteboard). Metode Voice Recognation pada alat EasyVR akan mengirim perintah pada arduino yang telah dihubungkan, sehingga masing-masing dari bagian motor stepper akan menggerakan lengan robot dalam perancangan alat ini lengan robot akan bekerja sesuai perintah suara yang diberikan pada pengucapan aplikasi handphone. Hal ini disebabkan karena alat telah terhubung dengan sensor suara. Kemudian dalam perancangan ini juga tersedia penghapusan papan secara manual melalui Interface tombol yang telah disediakan.

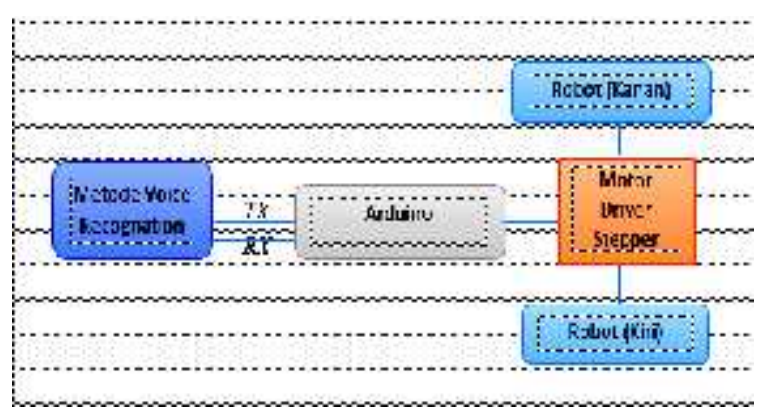

Gambar 2. Pemodelan Sistem Dengan Sensor Suara

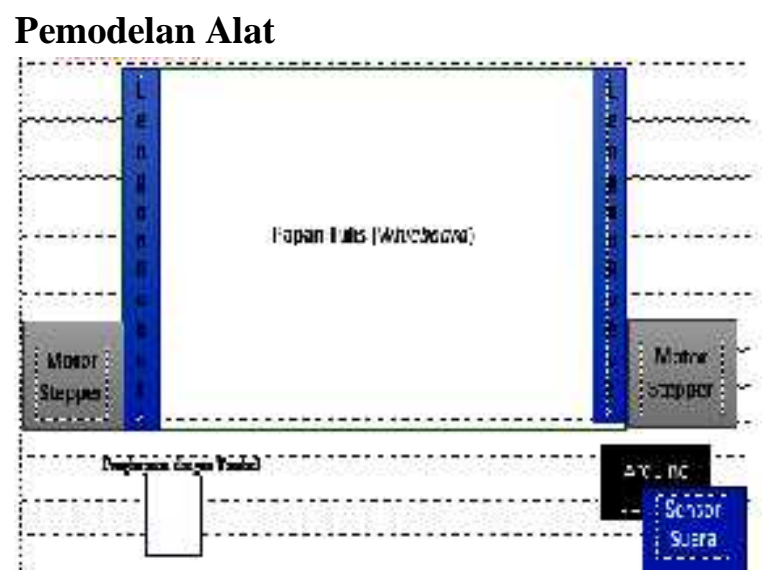

Gambar 3. Skema Rancangan Alat

Pemodelan alatnya seperti Gambar 3, papan tulis (whiteboard) akan memiliki dua lengan robot kiri dan kanan yang masingmasing dari lengan robot itu terdapat motor servo dan penghapus dimana motor stepper yang akan menggerakkan lengan robot tersebut telah dipasang sensor suara yang diolah pada arduino. Sehingga lengan robot akan bekerja sesuai perintah dari pengguna. Dengan Metode Voice Recognition ini akan memberikan kemudahan dalam melakukan penghapusan papan tulis.

Tahap pengujian alat dilakukan untuk mengetahui sistem yang telah dirancang yang menjadi tolok ukur keberhasilan sebagai solusi alat Smart Assistant Lengan Robot Penghapus Papan Tulis. Pengujian dilakukan di kelas Pendidikan Vokasional Mekatronika Fakultas Teknik Universitas Negeri Makassar. Untuk pengujian yang dilakukan dalam skala laboratorium pertama sensor diuji berdasarkan kalimat yang diucapkan dan diambil data dari penghapus yang dihasilkan untuk diolah oleh arduino untuk diklasifikasikan dan dijadikan sinyal kontrol. 


\section{HASIL DAN PEMBAHASAN}

Desain Smart Assistant awalnya terlihat tidak realistis dengan menggunakan lengan robot Humanoid. Setelah dipertimbangkan akhirnya diputuskan untuk mengganti desain Smart Assistant desain awal menjadi desain yang lebih lengkap pada penyempurnaan desain produk.

Kegiatan selanjutnya yang dilakukan yaitu membuat desain bagian-bagian alat 3D menggunakan aplikasi Solidwork kemudian dilakukan pencetakan bagian-bagian alat yang telah didesain menggunakan printer 3D.

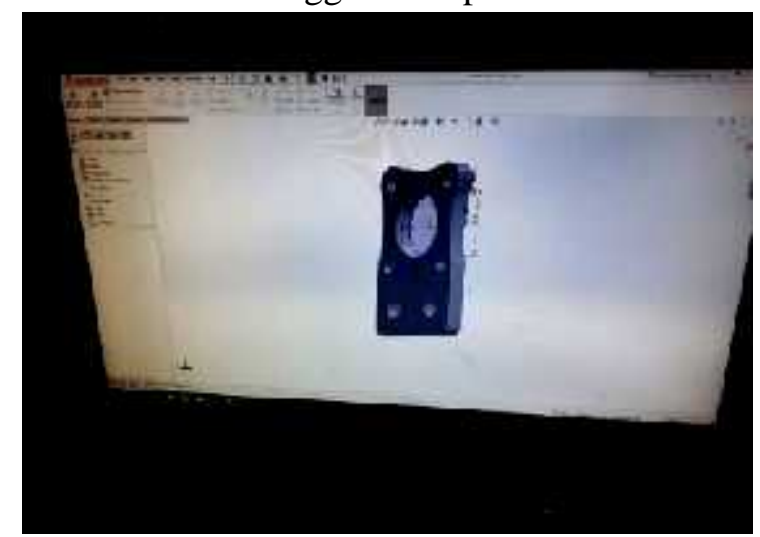

Gambar 4. Pencetakan Desain prnter 3D

Pembuatan produk dilakukan dalam beberapa tahap yaitu pemasangan bagian mekanik alat, pengerjaan bagian sistem elektronik alat, pemrograman, training suara EasVR commender, pembuatan interface penggunaan tombol manual dan pengujian alat.

Pada tahap pemasangan bagian mekanik alat, setelah melakukan pencetakan bagian alat menggunakan printer 3D langkah selanjutnya yang dilakukan adalah pengukuran sisi papan tulis dan aluminium kemudian memasang aluminium dan timming bell. Timming bell disini berfungsi sebagai penghubung motor steppper agar memudahkan pergerakan alat Smart Assistant pada sisi atas dan bawah papan tulis. Setelah pemasangan Aluminium dilanjutkan dengan memasang bagian alat-alat 3D yang telah kita buat sebagai penghubung alat dan Motor Servo.

Setelah bagian mekanik telah terpasang selanjutnya yang dilakukan yaitu merancang bagian sistem elektronik. Dalam perancangannya hal-hal yang dilakukan yaitu dengan mencetak bagian jalur PCB sebagai wadah pemasangan bagian komponenkomponen elektronika. Melakukan pengeboran pada PCB yang telah kita buatkan jalur. Saat pembuatan jalur dan pengeboran pada papan PCB selesai, dilanjutkan dengan pemasangan komonen elektronika.

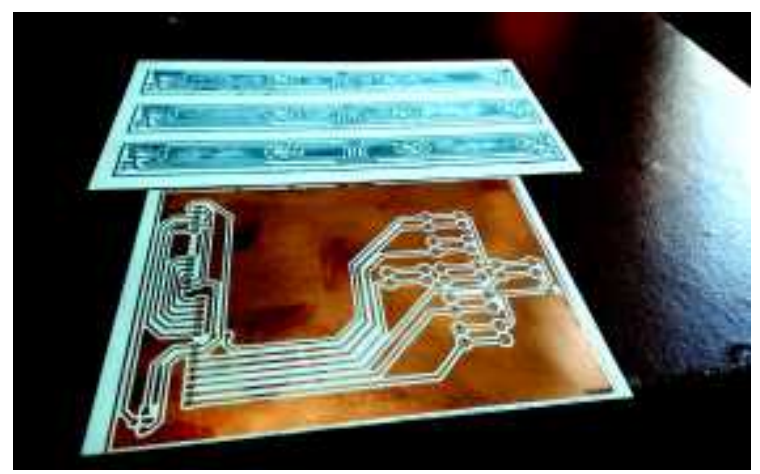

Gambar 5. Pembuatan Sistem Elektronika

Tahap pemrograman dilakukan dengan membuat program untuk setiap penggerak alat seperti, memprogram Motor Stepper dan Motor Servo pada Software Arduino sebagai pengendali kerja alat nantinya.

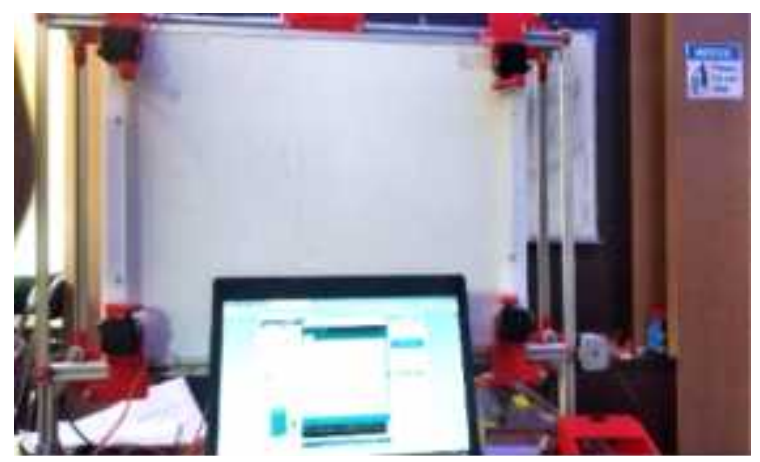

Gambar 6. Pemrograman

EasyVR sebagai sensor suara adalah alat yang akan menyimpan perintah. Training Suara EasyVR Commender dilakukan untuk mengisi perintah pada sensor suara alat seperti kata 'Hapus Kanan' dan 'Hapus Kiri'. Pengisian suara pada EasyVR dilakukan beberapa kali hingga sensor baru bisa menerima perintah suara yang diucapkan.

Membuat Interface panduan penggunaan tombol sebagai pemenuhan prinsip kerja alat 
secara manual. Dalam penggunaan alat ini bisa dilakukan penghapusan papan tulis dengan cara manual yaitu dengan menekan tombol sesuai dengan perintah yang ingin dilakukan pada saat proses penghapusan papan tulis.

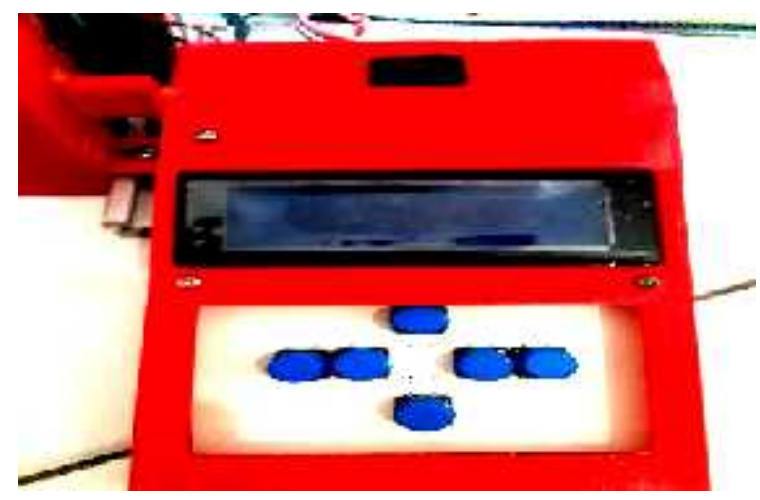

Gambar 7.Pembuatan Interface Tombol

Pengujian alat dilakukan beberapa kali dikarenakan dalam pembuatan Smart Assistant ini penulis melakukan pengaturan ulang pada sistem elektronik maupun perbaikan pada bagian mekanik alat, karena alat tidak bergerak atau tidak memberikan respon terhadap apa yang diucapkan pada Smart Assistant. Setelah dilakukan pengaturan ulang pada bagian mekanik maupun bagian elektronik alat kemudian dilakukan kembali pengujian alat beberapa kali sampai alat dapat bergerak sempurna dan menghapus tulisan-tulisan sesuai dengan prinsip kerja alat yaitu dengan pengucapan pada Assistant Handphone maupun pada tombol manual.

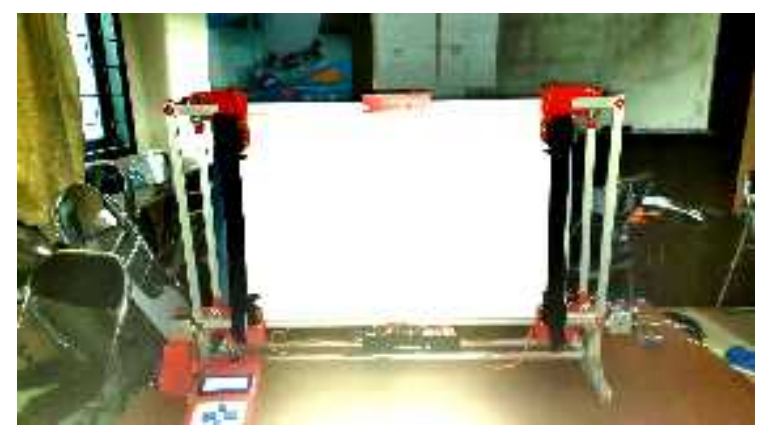

Gambar 8. Pengujian Alat

\section{SIMPULAN}

Penghapus papan tulis merupakan salah satu sarana pembelajaran yang telah umum digunakan oleh sekolah-sekolah yang ada di Indonesia. Papan tulis berbasis sensor suara ini menggunakan EasyVR. Proses kerjanya yaitu melalui perintah suara yang diberikan kemudian program akan memproses sehingga lengan robot akan bekerja sesuai dengan perintah yang diberikan. Smart Assistant ini dirancang untuk memudahkan proses dalam menghapus tulisan pada papan tulis. Perancangan Smart Assistant ini lebih efektif dimana program ini menggunakan sistem sensor suara dengan metode Voice Recognation, sehingga saat ingin menghapus papan tulis cukup dengan bersuara sesuai dengan perintah yang telah diprogram pada software arduino dan papan tulis akan dihapus oleh alat tersebut.

\section{DAFTAR RUJUKAN}

Gupta, Prateek. 2015. "Human Voice Cntrolled Home Appliances. International Journal of Advaced Research in Computer and Communication Engineering, 4, 142143.

Ichsan, I. Z., Dewi, A. K., Hermawati, F. M., \& Iriani, E. 2018. Pembelajaran IPA dan lingkungan: analisis kebutuhan media pembelajaran pada SD, SMP, SMA di Tambun Selatan, Bekasi. JIPVA (Jurnal Pendidikan IPA Veteran), 2(2), 131-140.

Imario, A., Sudiharto, D. W., \& Ariyanto, E. 2017. Uji Validasi Suara Berbasis Pengenalan Suara (Voice Recognition) Menggunakan Easy Vr 3.0. Prosiding SNATIF, 801-806.

Megasari, Rika. 2014. Peningkatan Pengelolaan Sarana dan Prasarana Pendidikan. Jurnal Administrasi Pendidikan, Vol. II, No.1 Tahun 2014.

Muhson, Ali. 2010. Pengembangan media pembelajaran berbasis teknologi 
informasi. Jurnal Pendidikan Akuntansi Indonesia, Vol.VIII, No.2 Tahun 2010.

Nurdyansyah, N. 2017. Sumber Daya dalam Teknologi Pendidikan. Universitas Muhammadiyah Sidoarjo.

Pujiriyanto. 2012. Teknologi Pengembangan Media dan Pembelajaran. Yogyakarta. UNY Press.
Xinyu, Li, et, al. (Ed). 2013. Voice Control Based Home Automation System. Diakses dari http://eceweb1.rutgers.edu/masic/books/ SE/projects/AutoHoME/2013. 